\title{
Antagonismo como identificação política
}

Desde o lançamento de Hegemony and socialist strategy, em 1985, a noção de antagonismo ocupa um lugar privilegiado no âmbito da teoria do discurso de Ernesto Laclau e Chantal Mouffe. Mesmo com o advento da categoria deslocamento, introduzida por Laclau em New reflections on the revolution of our time (1990) - a qual, como será aqui mostrada, assume papel central no empreendimento teórico como um todo -,o antagonismo mantém importância fundamental para a construção de lógicas, identidades e fronteiras políticas.

Neste trabalho, essa centralidade será contestada. Para isso, inicialmente, pretendemos, a partir de um percurso pelas principais obras de Laclau, identificar os elementos constituidores do antagonismo e confrontá-los com a leitura de seus críticos.

Após, considerando o discurso como um sistema, buscaremos localizar a função do antagonismo nesse discurso. Nesse momento, perceberemos que a ameaça antagônica é condição de possibilidade discursiva, mas de uma forma muito especial e regional, ou seja, antagonismo é aqui entendido tão somente como uma forma de identificação política, de identificação a partir de uma ameaça política. Apesar de ser responsável pelo desencadeamento de um processo articulatório de sentidos, que produzirá um discurso político,

\footnotetext{
* É professor do Departamento de Ciências Sociais da Universidade Federal de Pelotas (Pelotas, RS). E-mail:ddmendonça@gmail.com.
} 
sua função limita-se a isso, uma vez que, estando o corte antagônico externo ao discurso, ele não é capaz de produzir qualquer sentido neste. Portanto, os sentidos discursivos, positivos ou negativos, são internos ao discurso e produzidos de forma autorreferente pelo mesmo, cabendo ao antagonismo o papel de irritação sistêmica (Luhmann, 1998).

A noção de antagonismo social e a posterior primazia do deslocamento Antagonismo social aparece em Hegemony and socialist strategy (HSS) como parte de um contexto mais amplo em que Laclau e Mouffe (1985) apresentam seu projeto teórico pós-estruturalista conhecido como teoria do discurso político, teoria da hegemonia ou simplesmente teoria do discurso. ${ }^{1}$ A teoria do discurso deve ser lida como uma empreitada intelectual no sentido de fornecer ferramentas teóricas para a explicação de fenômenos sócio-políticos. Para tanto, Laclau e Mouffe (1985) apresentam um complexo de categorias analíticas apresentadas a partir da noção de discurso. Discurso, portanto, possui centralidade explicativa para esse projeto teórico.

Para os autores, discurso possui um sentido específico. Assim, entende-se que o discurso não é tão somente formado por características linguísticas, ou seja, essa noção não se restringe aos atos de fala ou ao que está estritamente escrito. $\mathrm{O}$ discursivo deve antes ser percebido como a união entre o que se fala e o que se escreve, mas também a forma como se age. Nesse sentido, se o discurso possui a sua evidente dimensão linguística, ele também carrega em si outra, ou seja, a dimensão extralinguística. O discurso, assim, deve ser entendido a partir da admissão de que toda prática social é uma prática significativa, pois que o social em si é um social significativo. Portanto, discurso possui uma dimensão ontológica. Nas palavras de Laclau:

O discursivo é, a partir de nossa perspectiva, o campo de uma ontologia geral, quer dizer, de uma reflexão acerca do ser enquanto ser. Isto supõe que as categorias lingüísticas deixam de estar ancoradas numa ontologia regional que as reduziria à fala e à escrita, e passam a constituir o campo de uma lógica relacional - fundada na substituição e na combinação, as duas formas primárias da articulação - que constituem o horizonte último do ser enquanto tal (Laclau, 2008b, p. 189).

Os elementos basilares da teoria do discurso não serão aqui apontados, tendo em vista que já foram desenvolvidos em muitas oportunidades por vários autores. Para uma visão geral dos pressupostos da teoria do discurso, ver Howarth (2000), Howarth e Stavrakakis (2000) e Torfing (1999). 
A tarefa da análise de discurso, portanto, pode ser resumida grosso modo da seguinte forma: o social deve ser compreendido a partir de lógicas discursivas e cabe ao analista conhecer as regularidades de sentidos desses sistemas discursivos. Para conhecer qualquer discurso, é necessário perceber as suas articulações e, para tanto, devem-se buscar no corpus discursivo os elementos que lhe dão identidade frente ao campo da discursividade, que é o espaço em que discursos disputam incessantemente sentidos.

A teoria do discurso é uma teoria política. O político, portanto, tem espaço privilegiado nesta proposta de análise. Aqui, "o político" deve ser percebido em toda a sua especificidade: para Laclau e Mouffe, constitui-se a partir de relações de poder medidas antagonicamente. ${ }^{2}$ Isso quer dizer que, se o social deve ser compreendido a partir de lógicas discursivas, essas lógicas devem ser analisadas a partir da ideia de discursos em luta, de discursos antagônicos. Assim, vejamos os elementos constituidores da lógica antagônica nos termos da teoria do discurso.

Para a compreensão da lógica antagônica, é preciso, primeiramente, compreender em que contexto a noção de antagonismo é elaborada por Laclau e Mouffe em HSS (1985). O objetivo central dos autores é o de demonstrar que as relações políticas não se constroem a partir de lutas entre identidades prontas. Mais especificamente: os autores entendem que não podemos considerar identidades políticas num sentido essencialista, ou seja, como constituídas antes da própria relação antagônica. O antagonismo, antes de ser uma relação entre objetividades já dadas, representa o próprio momento em que elas passam a ser constituídas. Assim, antagonismo é condição de possibilidade para a formação de identidades políticas - veremos a seguir que não é a única - e não meramente um campo de batalha que se forma entre duas forças com existências prévias.

Nesse sentido, Laclau e Mouffe exemplificam a lógica antagônica com o exemplo de um proprietário que expulsa os camponeses da sua terra.

\footnotetext{
Mouffe assim diferencia"o político"da"política":"[A]lguns teóricos como Hannah Arendt vêem o político como um espaço de liberdade e de deliberação pública, enquanto outros o vêem como um espaço de poder, conflito e antagonismo. Meu entendimento do 'político' claramente pertence a segunda perspectiva. Mais precisamente, esta é a forma como eu distingo o 'político' da 'política': por o político' eu entendo a dimensão do antagonismo a qual eu tomo como constitutiva das sociedades humanas, enquanto que por'política'eu significo uma série de práticas e instituições através das quais uma ordem é criada, organizando a coexistência humana no contexto de conflitualidade provido pelo político" (Mouffe, 2005, p. 9).
} 
Estabelece-se, aí, uma relação antagônica na medida em que o proprietário, a partir da ação da expulsão, impede que o camponês seja plenamente camponês (ele passa a constituir-se num camponês sem terra). Assim, quando estamos diante de uma lógica antagônica, não estamos diante de identidades pré-constituídas, mas daquelas que têm suas próprias constituições negadas, tendo em vista que a presença do outro é identificada como a condição da impossibilidade da plena constituição. Segundo os próprios autores: "[É] porque um camponês não pode ser um camponês que um antagonismo existe com o proprietário expulsando-o da sua terra (...). Na medida em que há antagonismo, eu não posso ser uma completa presença de mim mesmo" (Laclau e Mouffe, 1985, p. 125). Antagonismo é, portanto, uma experiência de negatividade, uma relação que apresenta o limite da objetividade ou da constituição plena das identidades. Nesse aspecto, David Howarth é claro:

A mera existência de antagonismos confirma que não há leis necessárias na história e não há agentes políticos universais motivados por interesses e identidades pré-constituídas. Ao invés disso, os antagonismos introduzem experiências sociais, tais como "fracasso", "negatividade" ou "falta", as quais não podem ser explicadas por nenhuma lógica de sociedade positiva ou essencialista. Eles revelam também a contingência e a precariedade de toda identidade e objetividade social, uma vez que toda identidade está sempre ameaçada por alguma coisa externa a ela (Howarth, 2000, p. 106).

Considerando que a teoria do discurso parte do pressuposto de que discursos são constituídos antagonicamente, ou seja, a partir da ameaça real oriunda de outros discursos, veja-se a forma como Laclau e Mouffe trabalham o conceito de antagonismo em HSS. Antagonismo é apresentado a partir da sua diferenciação teórico-analítica em relação às noções de "oposição real" (real opposition) e "contradição lógica" (logical contradiction), apresentadas por Lucio Colletti (1975), num esforço desse autor para iluminar tais categorias kantianas.

Assim, segundo a leitura de Laclau e Mouffe (1985), "oposição real” indica que 'A - B' são termos diferentes cujas positividades existem independentemente da relação que porventura eles possam ter entre si. A "oposição real” ocorre no terreno dos objetos reais (real objects). Como exemplo, os autores apresentam uma hipotética batida entre dois veículos e afirmam: “(....) [É] claro que um antagonismo não pode ser uma oposição real. Não há nada 
antagônico numa batida entre dois veículos: este é um fato material que obedece a leis físicas objetivas" (1985, p. 123).

Já a ideia de "contradição lógica" é representada pela fórmula 'A - não A'. Segundo essa noção, a relação entre dois termos esgota a realidade de ambos. A "contradição lógica" ocorre no terreno das proposições, dos conceitos. Contudo, contradição não redunda em antagonismo, pois "todos nós participamos de uma série de sistemas de crenças mutuamente contraditórios e nenhum antagonismo emerge destas contradições" (Laclau e Mouffe, 1985, p. 124).

Laclau e Mouffe, após apresentarem a diferença entre "oposição real" e "contradição lógica", passam a explicar o que tais categorias têm em comum e o que as faz, assim, completamente diferentes da noção de antagonismo. Nesse sentido, "oposição real" e "contradição lógica" "partilham algo, o fato de serem relações objetivas, entre objetos conceituais no segundo caso, e entre objetos reais no primeiro. Mas, em ambos os casos, isto é alguma coisa que os objetos já são, a qual faz a relação inteligível” (1985, p. 124, grifos do original). Em outras palavras, os autores afirmam que, seja num caso, seja no outro, se está diante de positividades, de objetos plenamente construídos, absolutamente prontos e inteligíveis. Assim, estamos falando de "relações objetivas", de "objetos já existentes", de "identidades completas" (Laclau e Mouffe, 1985).

No caso da relação de antagonismo, o que se propõe é algo completamente diferente. Aqui não se fala mais em "relações objetivas", em "objetos já existentes", em "identidades completas", mas do oposto. Antagonismo indica que “a presença do 'Outro’ me impede de eu ser totalmente eu mesmo” (Laclau e Mouffe, 1985, p. 125). Isto quer dizer que, quando se está diante de uma situação desse tipo, deve-se pressupor sempre uma relação entre identidades incompletas, justamente pelo fato de que a relação estabelecida entre ambas é antagônica. Enquanto que a "oposição real" e a "contradição lógica" têm de ser consideradas como sendo relações entre positividades, no antagonismo, os limites da própria objetividade são mostrados, pois o 'Outro' representa o limite dos sentidos alcançados por um determinado discurso, o que quer dizer, em última análise, que o antagônico se encontra fora, excluído e limitando a completa positividade daquilo que ele antagoniza. ${ }^{3}$

A noção de antagonismo como o único limite para a constituição plena de sentidos é válida no contexto específico de HSS. Em New reflections on the revolution of our time, veremos uma importante alteração no status dessa categoria com a introdução da noção de deslocamento. 
Dois exemplos extraídos de HSS ajudarão a esclarecer a noção. O primeiro deles diz respeito ao antagonismo que os autores denominaram "povo/ancien régime" na Revolução Francesa:

Com todo rigor, a oposição povo/ancien régime foi o último momento no qual os limites antagônicos entre duas formas de sociedade apresentaram-se eles mesmos - e com notada qualificação - na forma de claras e empiricamente dadas linhas de demarcação. A partir delas se demarca a linha entre o interno e o externo, a linha divisória na qual o antagonismo foi constituído na forma de dois sistemas de equivalências opostos [...] (Laclau e Mouffe, 1985, p. 151).

O segundo exemplo de antagonismo trata da emergência de "novos antagonismos", a partir da constituição de movimentos sociais:

Esses "novos antagonismos" são expressões de formas de resistência à acomodação, à burocratização e à crescente homogeneização da vida social [...] eles [os "novos antagonismos"] devem frequentemente se manifestar por meio da proliferação de particularismos e da cristalização de suas próprias demandas de autonomia. É também por essa razão que há uma tendência indefinível em direção à valorização das 'diferenças' e à criação de novas identidades, as quais tendem a privilegiar o critério 'cultural' (roupas, música, língua, tradições regionais etc.) (Laclau e Mouffe, p. 164).

No primeiro exemplo, temos a noção de antagonismo empregada para demarcar duas formas de sociedades absolutamente distintas: a "sociedade do ancien régime" antagônica à "sociedade do povo", em que um mundo impede a completa constituição do outro, no sentido da noção de antagonismo acima apresentada. Já no segundo, temos a utilização da mesma noção de antagonismo para caracterizar uma situação completamente diversa: movimentos sociais são constituídos para reivindicar suas demandas identitárias no contexto de um Estado democrático.

Aquilo a que se quer chamar a atenção neste momento, visto que as consequências do uso do termo antagonismo propriamente ditas serão exploradas na sequência deste artigo, é que estamos diante de duas situações distintas de antagonismo social. No primeiro caso, temos uma relação de separação entre dois mundos; no segundo, a relação antagônica pode ser considerada de forma mais localizada. São 
apresentados exemplos de antagonismos em distintos tecidos sociais: no primeiro caso, há um nível radical de antagonismo, tendo em vista estar-se diante de uma sociedade fraturada em dois projetos distintos: está-se diante, portanto, de uma situação de "anomia social". Já, no segundo caso, temos uma situação diversa: a sociedade em si não se encontra fraturada, mas apresenta pontos de antagonismos sociais em alguns de seus setores, que não são capazes de constituírem discursos hegemônicos a ponto de dividir a sociedade em duas e causar uma situação de "desordem generalizada" como foi o caso da relação antagônica entre povo e ancien régime.

Na sequência deste artigo, veremos que essa diferença entre antagonismos será em muito amenizada com a reformulação dessa noção por Laclau, no sentido de que o antagonismo não gera propriamente uma "exclusão radical" a ponto de considerar, como no caso do povo versus ancien régime, que ambos os polos constituem dois projetos de mundo absolutamente distintos. No entanto, por ora, seguir-se-á o argumento de Laclau em torno do desenvolvimento do conceito de "antagonismos sociais" a partir de seu trabalho posterior a HSS.

Nesse particular, em New reflections on the revolution of our time $(N R)$, Laclau rearticula o lugar da categoria antagonismo em seu sistema de pensamento. Se antes antagonismo era entendido como o limite da sistematização do sistema, ou seja, como o limite de sentido que o sistema discursivo poderia alcançar tendo em vista a presença do seu corte antagônico, a partir de NR a categoria perde essa dimensão. Laclau, sobretudo após crítica de Žižek (1993), admite que o antagonismo não pode ser o limite da constituição de sentidos de um sistema, pois que a própria condição do outro antagônico já infere um tipo de simbolização, uma forma de produção de sentidos. Assim, "o que eu não sou" e "contra o que eu me antagonizo" já fazem parte de um sistema de significação. Em uma entrevista para Yannis Stavrakakis, Laclau argumenta:

Havia certa ambiguidade na forma como a categoria de antagonismo foi formulada em Hegemony and Socialist Strategy .... Hoje eu acredito que a constituição do outro como antagônico já pressupõe uma certa inscrição discursiva - em outras palavras, conceber o outro como um inimigo pressupõe uma identificação a priori de nós 
mesmos com a posição particular na estrutura da ordem Simbólica [isto também pressupõe, em alguns casos, a construção imaginária-fantasmática de ambos os pólos antagônicos]. É por isso que em meu mais recente trabalho eu movi minha atenção à categoria de "deslocamento" a um nível anterior da de "antagonismo" (Stavrakakis, 2003, p. 324).

A introdução da categoria de "deslocamento" promove uma importante mudança na teoria do discurso de Laclau. Inicialmente, o autor retira o status privilegiado do antagonismo como o único responsável pela constituição das relações sociais, que permanecem políticas e conflituosas. Antagonismo aparece, a partir de $N R$, como parte de um sistema de significação, como condição de identificação, como algo simbolizado. O outro antagônico, o inimigo, não é mais o "não simbolizado", mas a própria possibilidade da simbolização, da identificação.

Como já dito, a partir de NR, Laclau desenvolve a categoria de "deslocamento" e atribui a ela uma centralidade no conjunto de noções que compõem a sua teoria. A utilização da noção de deslocamento marca claramente o casamento da teoria do discurso com a psicanálise lacaniana. Tal engajamento permite o desenvolvimento da ideia de subjetividade política como alternativa ao deslocamento estrutural. Vejamos tais movimentos.

Primeiramente, o casamento da perspectiva de Laclau com os desenvolvimentos de Lacan já vinha se desenhando desde a década de 1980. Em HSS, por exemplo, as noções de pontos nodais, sutura e articulação já anunciavam essa tendência. No entanto, a introdução da ideia de deslocamento marca uma importante virada teórica. Assim, se em HSS, Laclau e Mouffe (1985), criticando Foucault, "rejeitam a distinção entre práticas discursivas e não discursivas", afirmando que "cada objeto é constituído como um objeto de discurso, na medida em que nenhum objeto é dado fora de cada condição de emergência discursiva" (1985, p. 107), a partir de NR a situação muda sensivelmente. Mas em que sentido ela muda?

Segundo Laclau, todo objeto continua sendo um objeto de discurso, tendo em vista que, mesmo que sua existência seja dada por sua materialidade, ela também está marcada pelo contexto de sua constituição. Por exemplo, uma bola tem indiscutivelmente a sua existência material, mas ela está acompanhada de um contexto simbólico-discursivo. Assim, será uma bola de futebol, de basquete, de vôlei, de tênis, dependendo do contexto discursivo 
no qual ela está imersa. Nesse sentido, a crítica ao não-discursivo foucaultiano permanece a mesma para Laclau. O que muda com a introdução da categoria de deslocamento não é, portanto, o status e o funcionamento da lógica do discurso e da constituição da significação, mas como lidar com uma situação na qual a própria possibilidade de significação chega ao seu limite. O deslocamento é o instante preciso da impossibilidade da significação. O deslocamento é o exato momento em que Laclau promove o encontro de sua teoria com o Real lacaniano. ${ }^{4} \mathrm{O}$ Real lacaniano é justamente o não simbolizável, a impossibilidade da produção de sentidos. Sobre o Real em Lacan, Homer argumenta:

A dificuldade de entender o real é parcialmente devido ao fato de que ele não é uma "coisa"; ele não é um objeto material no mundo, ou no corpo humano ou mesmo na "realidade". Para Lacan, nossa realidade consiste de símbolos e de processos de significação. Portanto, o que nós chamamos de realidade está associado com a ordem simbólica ou com a "realidade social". O real é o desconhecido que existe no limite deste universo sócio-simbólico e está em constante tensão com ele (Homer, 2005, p. 81).

Como dissemos acima, o deslocamento, segundo Laclau, é exatamente o momento do Real, ou seja, do desconhecido, da impossibilidade de significação. Se antes Laclau e Mouffe (1985) entendiam esse momento como o do antagonismo - o que Žižek corretamente refuta, ${ }^{5}$ tendo em vista, como vimos, ser o antagonismo parte do próprio processo de significação -, a partir de

\footnotetext{
4 Stavrakakis é absolutamente claro neste aspecto:"(...) [O] deslocamento, substituindo o antagonismo como central para o político, pode apenas ser entendido como um encontro com o real lacaniano por excelência. Ambos são irrepresentáveis; ambos são ao mesmo tempo traumáticos/interrompidos e produtivos. Deslocamentos são traumáticos no sentido que eles 'ameaçam identidades' e são produtivos no sentido que eles servem como 'a fundação na qual novas identidades são constituídas'. Similarmente, o real traumático sempre interrompe todas as tentativas de simbolização; e, ainda, ele nunca cessa de chamar por novas simbolizações. Está claro que a emergência desse conceito de deslocamento real como central para o político é um dos mais importantes produtos do diálogo de Laclau com a psicanálise e aquele que diretamente liga o seu argumento sobre a impossibilidade da sociedade com a irredutibilidade do real no discurso lacaniano" (2003, p. 324).

Žižek percebe essa tentativa dos autores de HSS de dar o status do Real lacaniano à noção de antagonismo: "O real conseguiu de Hegemonia se cristalizar no conceito de 'antagonismo social': longe de reduzir a realidade a um tipo de jogo de linguagem, o campo sócio-simbólico é concebido como estruturado em torno de uma certa traumática impossibilidade, em torno de uma fissura que não pode ser simbolizada" (1993, p. 257).
} 
$N R$, o momento dessa impossibilidade está representado pela noção de deslocamento. A introdução dessa categoria esclarece o status pós-estruturalista da teoria do discurso, tendo em vista que o jogo estrutura-agente aparece em formato mais preciso, dando lugar à ideia de subjetividade política.

Assim, pensar uma determinada estrutura discursiva é pensar num conjunto de sentidos hegemônicos sedimentados que constituem uma determinada ordem. Evidentemente essa ordem hegemônica pressupõe uma série de antagonismos, uma vez que politicamente toda constituição discursiva, se por um lado é um ato de inclusão de sentidos, por outro lado representa uma série de outras exclusões. Dessa forma, por exemplo, um estado democrático apresenta uma série de características constituidoras (sufrágio universal, direitos individuais etc.), ao mesmo tempo em que pressupõe as suas próprias exclusões (discursos xenófobos, racismo etc.). É claro que não estamos tratando de discursos plenamente constituídos (essencialistas), uma vez que estes são sempre passíveis de ressignificações e tais ressignificações refletem a própria validade da noção de hegemonia (para haver hegemonia deve necessariamente haver contra-hegemonia). Assim, um discurso democrático está sempre sendo ameaçado por práticas nãodemocráticas, e a própria ideia de democracia é algo em constante negociação e objeto de incessantes lutas.

Dessa maneira, a lógica discursiva proposta por Laclau e Mouffe (1985) é o resultado de práticas articulatórias que fixam sentidos parciais por meio de pontos nodais que articulam elementos/momentos. Assim, qualquer constituição discursiva, pensada em termos de sistema discursivo, simboliza, estrutura e reestrutura sentidos, tendo em vista que estamos diante de um processo de constante significação.

No entanto, o momento do deslocamento é outro. Reside justamente no momento em que a estrutura não consegue processar, semantizar algo novo, algo que, portanto, lhe foge à significação. O deslocamento é, portanto, o momento do Real, o momento em que o extradiscursivo apresenta o limite do sentido. Uma estrutura deslocada é uma estrutura que experimenta um momento de crise, um momento em que é posta radicalmente em xeque. O deslocamento é anterior, é externo à significação, portanto, externo ao antagonismo; é uma experiência traumática que desajusta a estrutura, a qual precisa ser recomposta a partir de novos processos de significação. Assim, estamos falando de processos de significação substituindo outros processos 
de significação, em razão de uma falha estrutural provocada pelo deslocamento, ou seja, justamente pela impossibilidade de significação. ${ }^{6}$

Se não podemos alcançar o Real, pois o real não é passível de significação, o deslocamento é, nesse sentido, a evidência da incompletude da estrutura, da impossibilidade de sua completa estruturação ou sutura. Se o Real é uma instância existente, mas não significável, e se as estruturas estruturam-se a partir de processos de significação, então, no limite, estamos sempre diante de estruturas incompletas, marcadas pela perene possibilidade do trauma deslocatório. Numa expressão: são estruturas da falta. É nesse momento de falha na estrutura que o sujeito toma seu lugar de destaque. Conforme Laclau, "o lugar do sujeito é o lugar do deslocamento. Portanto, longe de o sujeito ser o momento da estrutura, ele é o resultado da impossibilidade de constituir a estrutura como tal - quer dizer, como objetividade" (Laclau, 1993, p. 57). Segundo Howarth:

É este momento de "falha" da estrutura para conferir identidade aos atores sociais que "compele" o sujeito para agir. Neste sentido, o sujeito não é simplesmente determinado pela estrutura, nem, contudo, ele constitui a estrutura. O sujeito é forçado a tomar decisões (...) quando identidades sociais estão em crise e estruturas necessitam ser recriadas. É no processo desta identificação que as subjetividades políticas são criadas e formadas (Howarth, 2000, p. 109).

Assim, num sentido pós-estruturalista - ou seja, em que a estrutura estrutura o sujeito, mas que também é, em certa medida, por ele estruturada -, é que existe a resposta ao trauma do deslocamento. Tomando-se uma estrutura deslocada, surge a necessidade de sua reestruturação a partir de novos sentidos ou da reativação de sentidos já existentes. É nesse momento que a categoria de antagonismo assume seu lugar definitivo na teoria do discurso: como parte de processos de significação e de constituição de novas formas de inclusão, mas também de exclusão de sentidos discursivos. Nas palavras de Laclau:

\footnotetext{
No glossário de Torfing sobre os principais conceitos desenvolvidos pela teoria do discurso, o deslocamento é assim conceituado e exemplificado:"Deslocamento: uma desestabilização de um discurso que resulta da emergência de eventos os quais não podem ser domesticados, simbolizados ou integrados pelo discurso em questão. Por exemplo, a concorrência de inflação e de desemprego no início dos anos 1970 deslocou a ortodoxia keynesiana, a qual, basicamente afirmava que a'estagnaflação' nunca ocorreria. Igualmente, o processo de globalização tende a deslocar a ideia da nação-estado como o terreno privilegiado para a atividade econômica" (1999, p. 301).
} 
(...) [A] resposta ao deslocamento da estrutura será a recomposição da mesma por parte das diversas forças antagônicas em torno de pontos nodais de articulação precisos. O centramento - a ação de centrar - só é possível, portanto, na medida em que há deslocamento e desnivelamento estrutural. Novamente: o deslocamento é a condição de possibilidade e de impossibilidade de um centro (1993, p. 57).

Assim, o (re)centramento da estrutura, segundo Laclau, passa necessariamente pela constituição de novos antagonismos e de novos processos hegemônicos. Apesar de antagonismo social ser uma categoria que perdeu a sua centralidade na teoria do discurso para a de deslocamento, ela é ainda a conditio sine qua non, para Laclau, em relação à possibilidade de existência de discursos. No entanto, outros autores dessa mesma matriz teórica colocam em questão o antagonismo como a única possibilidade de constituição de discursos políticos. Nesse sentido, são de particular importância os argumentos de Aletta Norval e Urs Stäheli, os quais serão desenvolvidos na próxima seção deste trabalho.

\section{Questionando as fronteiras antagônicas}

Para Laclau, a possibilidade da política é a possibilidade dos seus limites (Laclau, 1993). Limites, para o autor, são necessariamente limites antagônicos, ou seja, um discurso, uma identidade política se constitui na medida em que esta identifica o seu inimigo. A centralidade da noção de antagonismo vem justamente daí: do fato de ser apresentada como a única forma admitida por Laclau para a construção de lógicas políticas.

Em geral, os trabalhos empíricos que têm por marco teórico e epistemológico a teoria do discurso partem justamente desse pressuposto. ${ }^{7} \mathrm{O}$ limite antagônico é dado como algo inerente a toda e qualquer relação política. A primeira tarefa dos analistas, nesse particular, é a da identificação de casos em que a relação antagônica pode ser encontrada. Assim, pode-se dizer que ficamos entre duas alternativas: $1^{\circ}$ ) ou podemos, de fato, encontrar limites antagônicos em todas as relações políticas existentes e, neste caso, concordando com Laclau e Mouffe (1985), teremos de admitir que o antagonismo faz parte da ontologia do político ou; $2^{\circ}$ ) o uso da categoria antagonismo em

As coletâneas organizadas por Laclau (1994), Howarth, Norval e Stavrakakis (2000) e por Howarth e Torfing (2005) apresentam uma série de usos da teoria do discurso para análise de processos sociais e políticos em que a categoria de antagonismo mantém a sua centralidade. 
particular e a aplicação da teoria do discurso em geral para a compreensão dos fenômenos políticos estão limitados aos processos políticos e sociais em que relações antagônicas são detectadas.

Se, no nível analítico, a categoria antagonismo não tem a sua primazia contestada, do ponto de vista teórico ela vem sofrendo alguns questionamentos. O questionamento do antagonismo levado ao seu limite não seria uma mera crítica a uma categoria regional entre outras tantas articuladas pela teoria do discurso. Como o limite antagônico, segundo Laclau, é central para a constituição das próprias relações políticas, desconstruir essa categoria significa pôr em xeque a própria possibilidade da teoria como um todo, justamente tendo em vista o status central que ela ocupa neste contexto teórico. As críticas, aqui, à ideia de fronteiras ou de limites antagônicos têm sido feitas, mas, pelo menos por ora, não chegam ao ponto de ameaçar o projeto teórico como um todo. Pelo contrário, mesmo a despeito das críticas formuladas em torno da noção de antagonismo, parece que esta categoria tem conseguido ser sustentada por Laclau no que concerne a sua posição central em seu empreendimento teórico. A análise de Aletta Norval em relação à questão das fronteiras políticas no âmbito da teoria do discurso é uma das contestações mais importantes à centralidade do antagonismo que têm sido levadas a efeito entre os principais comentadores de Laclau.

Nesse sentido, Norval (2000) estabelece sua crítica em termos de fronteiras políticas, concentrando-se, sobretudo, na discussão entre fronteira e individualização de identidades políticas. A autora elabora seu argumento em função da constatação básica de Laclau e Mouffe (1985) de que é justamente a partir da constituição ou da dissolução de fronteiras políticas que as identidades são construídas ou fragmentadas. Assim, seguindo o argumento de Norval (2000), pode-se inferir que existe, para Laclau e Mouffe (1985), um nexo de causalidade entre a constituição identitária e a formação de fronteiras, nexo que a autora contesta. ${ }^{8}$ Assim, a autora entende que é necessário distinguir entre "uma lógica geral de individualização da identidade" (2000, p. 219) e a formação de fronteiras políticas, no sentido de autonomizá-las entre si da seguinte forma: [individualização de identidade] $\neq$ [formação

Em trabalho publicado anteriormente, a autora apresenta exatamente a mesma constatação, ou seja, segundo Norval, para Laclau e Mouffe, "é através da consolidação ou da dissolução de fronteiras políticas (...) que as formações discursivas em geral e as identidades sociais e políticas especificamente são construídas ou fragmentadas" (Norval, 1997, p. 54). 
de fronteiras políticas]. Como vimos, baseando-se na teoria de Laclau, evidentemente não estamos diante de quaisquer fronteiras políticas, mas de fronteiras antagônicas, as quais privilegiam o momento da negatividade, no sentido de que o meu inimigo é responsável pela construção da minha própria identidade. Norval é clara nesse sentido:

Há na teoria do discurso uma tendência de privilegiar o momento da negatividade, da construção de fronteira e do desenvolvimento de antagonismos. Em nenhum outro lugar isto está mais claro do que no fato de que a relação "amigo/inimigo" é tratada como constitutiva da política como tal. Se, de fato, há política apenas onde existem fronteiras e se as fronteiras consistem na construção de relações antagônicas "amigo/inimigo", então o momento da formação da fronteira está inequivocamente privilegiado em relação às dimensões diferenciais da identidade (Norval, 2000, p. 223).

Em outro trabalho, além da negatividade do momento da constituição identitária, Norval reclama da ausência de traços positivos nessa mesma constituição, conforme Laclau e Mouffe. Em seus próprios termos:

A produção de efeitos de fronteira, para Laclau e Mouffe, então, passa a existir através da operação de sistemas de equivalência os quais constroem o além de como aquilo que não se é. Identidade não é, assim, individualizada através de uma série de elementos positivos, mas através da criação de fronteiras políticas as quais dividem o espaço político em construções equivalenciais e externas (1997, p. 60).

Notemos, a partir dos dois excertos de Norval, primeiramente, que a conditio sine qua non para a existência de uma identidade política, nos termos da teoria do discurso de Laclau e Mouffe, depende da existência de limites antagônicos, sempre negativos. Além disso, tomando especificamente o segundo trecho citado, a autora reclama a ausência de traços positivos das próprias identidades para esses mesmos autores.

A partir dos movimentos empreendidos por Norval, podemos aduzir que, se a existência de uma identidade política depende de seu corte antagônico (dimensão negativa) e se esta dimensão negativa é externa ao discurso antagonizado e é privilegiada "em relação às dimensões diferenciais da identidade", então, logicamente, se a interpretação de Norval está correta (e achamos que está!), podemos concluir que o que está fora do sistema de constituição de uma identidade política pode acabar nela produzindo 
sentidos . Assim, então, Laclau e Mouffe estariam incorrendo num erro lógico, ou seja, estariam afirmando que é possível a produção de sentidos num sistema discursivo por aquilo que está fora de seus limites, quando, na verdade, os sentidos de um sistema (por isso que ele se individualiza como tal) são produzidos internamente e nunca por algo estranho a ele, ainda mais se levarmos em consideração o exterior antagônico. Antagonismo aqui não seria meramente uma forma de identificação política negativa que serviria de condição de possibilidade para uma determinada construção discursiva e uma limitação na própria produção de sentidos por esse discurso; ele seria a própria produção de sentidos, o que é logicamente impossível, pois isso afetaria a identidade do discurso como tal.

Laclau não admitiria que algo externo ao discurso fosse capaz de atribuir sentidos a ele, justamente tendo em vista o raciocínio que utilizamos, ou seja, o de que a produção de sentidos está limitada pelo limite do próprio sistema. ${ }^{9}$ Contudo, a noção de antagonismo guarda uma estranha ambiguidade não resolvida pelo autor. Essa ambiguidade reside justamente no fato de que o antagonismo permanece como um limitador na produção de sentidos de um sistema discursivo. Se ele é um limitador, se o discurso antagônico é parte de um processo simbólico-discursivo, se o autor não dá a devida atenção aos sentidos positivos de uma formação discursiva, então o que mais produziria sentidos num discurso? Se não é o antagonismo - que está fora dos limites sistêmicos e tem como função possibilitar a existência discursiva pela ameaça que representa -, então teríamos logicamente de admitir que não somente os sentidos negativos mas também os positivos, ou seja, aqueles que definem o que a identidade é, aqueles que também a individualizam, são articulados discursivamente.

A ausência do tratamento de sentidos positivos produzidos por sistemas discursivos antagônicos pela teoria de Laclau ocorre devido ao fato de que o autor, que apresenta uma excessiva preocupação com os limites e com o papel do antagonismo na formação de lógicas políticas, simplesmente não faz uma discussão sistêmica acerca do que ocorre no interior de um discurso que tem marcada a sua existência pela presença do antagonismo. Toda a preocupação ontológica em defender a existência da política a partir de lógicas antagônicas acaba limitando a sua proposta em termos

Laclau claramente já disse isso, quando afirmou que, "se a possibilidade mesma da significação é o sistema, a possibilidade do sistema é equivalente à possibilidade de seus limites" (Laclau, 1996, p. 71). 
de investigações teóricas que deem conta de como funcionaria um sistema discursivo marcado pela exclusão antagônica. Se tal investigação fosse levada a efeito, certamente não somente traços negativos seriam encontrados, mas elementos positivos inevitavelmente passariam a fazer parte das preocupações teóricas de Laclau.

Mesmo considerando que o central no argumento de Laclau e de Mouffe em termos de fronteiras políticas é a divisão em "nós" versus "eles", vista de forma antagônica, Norval vislumbra leituras alternativas nas obras desses autores posteriores a HSS com o objetivo de separar a individualização das identidades da questão das fronteiras. Para tanto, a autora argumenta que, do lado de $\mathrm{Laclau}^{10}$, a introdução da categoria deslocamento em NR abre a possibilidade para considerar o antagonismo como apenas uma entre outras possibilidades de individualização identitária, tendo em vista que, a partir dessa obra, não é mais o antagonismo que revela o limite do social, o limite do sentido, mas sim o deslocamento. Nesse sentido, se o deslocamento revela esse limite e se o antagonismo passa a ser visto como parte de um sistema de significação, por que não pensar o antagonismo como apenas uma das possibilidades para a individualização de identidades? Em termos teóricos, esse parece ser um argumento apropriado. ${ }^{11}$ Nas palavras de Norval:

Em New reflections on the revolution of our time, o conceito de deslocamento assume o papel de indicar os 'limites do social', reservado antes ao antagonismo, com a consequência de que o antagonismo não mais coincide simplesmente com o momento da individualização da identidade. Em vez disso, ele se torna uma articulação possível entre muitas. A partir desta leitura, o lugar da formação da identidade pode ser considerado um lugar de indeterminação. Em outras palavras, este é um espaço aberto considerando uma variedade de formas as quais a relação entre o "eu" e o "outro" pode ser concebida. Deste lugar, torna-se possivel pensar a divisão do social em termos diferentes da relação amigo/inimigo (Norval, 2000, p. 223, grifos do original).

\footnotetext{
10 O argumento de Norval, em termos dos desenvolvimentos posteriores de Chantal Mouffe - os quais têm a ver com a conhecida diferenciação entre as relações antagônicas e agônicas e a substituição dos inimigos pelos adversários, que não são centrais para o desenvolvimento do argumento presente neste artigo -, pode ser encontrado em Norval (2000, p. 224) e em Mouffe (2003, 2005).

11 Em Fronteirs in question, Norval sugere, a partir da leitura de Derrida e do último Wittgenstein, que é perfeitamente possível pensar a constituição de identidades completamente desvinculada do estabelecimento de fronteiras antagônicas, sem que tais constituições identitárias recaiam no essencialismo tão criticado por Laclau e Mouffe (1985). Para o desenvolvimento completo do argumento da autora, ver: Norval (1997, p. 68-75).
} 
Se o argumento de Norval com relação à distinção entre constituição discursiva/identitária e fronteiras localiza-se externamente ao funcionamento das lógicas discursivas em si, ou seja, a autora não considera - e nem precisa considerar para justificar tal distinção - o funcionamento interno dos discursos, a crítica de Stäheli (2008) está focada justamente nesse particular. Tomando-se por base a teoria dos sistemas sociais de Niklas Luhmann (1998), o autor - mesmo considerando acertado o argumento de Norval no sentido da necessidade de diferenciar conceitualmente a ideia de individualização identitária/discursiva da de antagonismo - critica o enfoque da autora, afirmando que a sua oposição a Laclau e Mouffe, na intenção de "relativizar a lógica do antagonismo debilita a ideia do exterior constitutivo e substitui este conceito com uma vaga ideia de indeterminação" (2008, p. 294). Stäheli, buscando manter as noções de Laclau de exclusão e de cadeias de equivalências para a constituição dos limites do sistema discursivo, argumenta:

A natureza excludente de todo discurso não é automaticamente antagônica, mas a exclusão constitutiva cria deslocamentos no discurso em questão. De certo modo, os discursos se fecham mediante operações conectivas - como sugere a teoria dos sistemas - que deixam sem marcar o exterior. O discurso se torna antagônico somente se os deslocamentos se articulam de maneira antagônica. Em termos da teoria dos sistemas: o discurso, para chegar a ser antagônico, tem de ver-se e descrever-se como antagonicamente constituído (2008, p. 294).

Seguindo o argumento de Stäheli, é interessante perceber que toda a produção de sentidos ocorre necessariamente no interior do próprio sistema. Um sistema é um sistema porque produz seus sentidos internamente (princípio da autorreferência), o que faz com que ele se diferencie do meio ambiente. Para esta perspectiva, um sistema sempre promove um momento de exclusão absolutamente necessário para a sua identificação. É nesse sentido que é fundamental, conforme Stäheli, a manutenção da noção de exterior constitutivo, a qual Norval parece pôr em questão para fins da individualização da identidade. Diante de sistemas discursivos, estamos diante de sistemas, e estes, conforme Luhmann (1998), não podem produzir sentidos além de seus próprios limites. $\mathrm{O}$ antagonismo, assim, deve ser visto como uma das formas de exclusão sistêmica, mas não a única. Tal compreensão gera uma interessante forma de pensar o conceito. 
Desta forma, o momento do antagonismo é um momento de percepção interna de uma ameaça ao sistema. Se o exterior constitutivo deve ser mantido para a garantia da operação sistêmica de produção de sentidos e se nem todo o exterior constitutivo torna-se sinônimo de antagonismo, pois que o antagonismo seria um subtipo de múltiplas exterioridades possíveis, para que um sistema discursivo opere antagonicamente ele tem de se descrever como tal. Resumindo: é possível pensarmos o antagonismo simplesmente como uma forma de identificação que tencionará as estruturas do sistema neste sentido. As consequências dessa afirmação, centrais para o nosso argumento, sobretudo pensando na possibilidade de aplicação da noção de antagonismo em pesquisas empíricas, serão desenvolvidas na próxima seção deste trabalho.

\section{O antagonismo em seu lugar}

Pensar a noção de antagonismo no âmbito da teoria do discurso requer compreendê-la como parte de uma lógica de construção de discursos políticos. Vimos que, se em HSS antagonismo era visto como o limite de toda a objetividade, ou seja, era percebido por Laclau e Mouffe como a impossibilidade de uma determinada identidade constituir-se plenamente justamente pela presença do outro antagônico - numa clara preocupação dos autores de conceber identidades políticas não-essencialistas -, a partir de $N R$, Laclau retira dessa categoria tal primazia constitutiva do limite da objetivação. Com a introdução da noção de deslocamento, o autor claramente desloca o antagonismo para o nível da produção discursiva de sentidos. Em suas próprias palavras:

Em Hegemonía y estrategia socialista, a noção de limite é mais ou menos sinônima de fronteira antagônica. A objetividade somente se constitui através da exclusão radical. Logo, contudo, adverti que esta assimilação apresentava dois flancos débeis. Primeiro, que o antagonismo já é uma forma de inscrição discursiva - quer dizer, de domínio - de algo mais primário que, desde Nuevas Reflexiones sobre la revolución de nuestro tiempo em diante, comecei a chamar "deslocamento". Nem todos os deslocamentos necessitam ser construídos de maneira antagônica. A segunda fraqueza é que o antagonismo não equivale à exclusão radical. O que ele faz é dicotomizar o espaço social, mas ambos os lados são necessários para criar um espaço único de representação (Laclau, 2008, p. 393-394). 
O trecho acima, extraído da resposta que Laclau dá ao argumento desenvolvido por Stäheli ${ }^{12}$, nos permite pensar em torno da categoria de antagonismo a partir de algumas premissas importantes. Primeiramente, antagonismo tem de ser entendido como parte de um processo discursivo, ou seja, de um processo de significação. Isso quer dizer que o antagonismo é significado sistemicamente e não como afirmava Laclau em HSS, como sendo essa categoria a representação do limite da própria possibilidade de significação (esse limite é dado pelo deslocamento). Outro fator importante da passagem acima diz respeito à função do antagonismo, ou seja, ele serve para provocar uma dicotomização no espaço social, mas ao mesmo tempo essa dicotomização "não equivale à exclusão radical". De que forma podemos aduzir consequências desses dois pontos?

Primeiramente, é necessário entender que os dois pontos estão interligados. Assim, se antagonismo é parte de um sistema de significação, ele tem a função de dicotomizar o espaço discursivo em discursos antagônicos. Se antagonismo é, ao mesmo tempo, parte de um sistema de significação e possui como função a de dicotomizar o espaço social, sem que isso represente necessariamente uma exclusão radical, temos de entender estritamente do que estamos falando. A função de dicotomizar o espaço social é uma função discursiva possível, mas não necessariamente a única. Nesse sentido, não podemos reduzir os sentidos de um discurso político antagônico a sua mera dimensão antagônica. Parece ser absolutamente razoável supor que um discurso antagônico possa também articular sentidos positivos (de alianças, de propostas, de dimensões simbólico-fantasmáticas em ideologias que guiam ações políticas identitárias etc.).

Dessa maneira, o antagonismo deve ser visto como a condição de possibilidade discursiva, na medida em que a dicotomização ocorre porque, na verdade, o antagonismo é uma forma de identificação de identidades políticas. O outro antagonizado faz parte do processo de significação, não porque seus sentidos estão incluídos no discurso, mas porque seus sentidos geraram a produção de sentidos antagônicos a eles. Por exemplo, um discurso racista numa determinada comunidade poderia constituir um

\footnotetext{
12 Na verdade, não se tratou de uma resposta exclusiva às observações de Stäheli, mas de um texto elaborado por Laclau visando responder todos os comentários críticos submetidos a sua obra na coletânea organizada por Critchley e Marchart (2008).
} 
discurso antirracista; não que os sentidos racistas seriam articulados no interior do discurso antirracista, mas justamente o contrário. O papel do antagonismo, nas palavras de Laclau, é gerar a dicotomização discursiva. Em nossas palavras, antagonismo tem a função de gerar um tipo específico de identificação política.

Do que foi dito, devemos considerar, portanto que o antagonismo não nos diz o que o sistema discursivo é, mas justamente aponta o que ele não é. Contudo, isso não quer dizer necessariamente que o discurso é estritamente o oposto do seu polo antagônico, tendo em vista que nada impede que aspectos positivos de identificação sejam também articulados discursivamente. Isso porque devemos ter absolutamente claro que, se se pode dizer que o antagonismo é causa da constituição discursiva pelo processo de identificação que ele promove, não podemos afirmar que ele é a própria articulação de sentidos. Não podemos também afirmar que o antagonismo interfere na produção de sentidos de um determinado sistema além do ponto que gerou a sua identificação, pois se o antagonismo dicotomiza o espaço social em dois sistemas distintos, esses sistemas produzem seus sentidos independentemente um do outro. Se o antagonismo constituísse sentidos no sistema com o qual ele se dicotomiza, teríamos de admitir, então, que não estaríamos diante de dois sistemas, mas de um só, pois dicotomizar significa produzir dois sistemas diferentes com regras de funcionamento distintas. Nesse sentido, entendemos que a função do antagonismo é a de irritar, no sentido proposto por Luhmann (1998), as estruturas sistêmicas a ponto de que elas se auto-organizem a partir da identificação da hostilidade.

Ligada à dicotomia do espaço social está a ideia de que o antagonismo não equivale a uma exclusão radical, tendo em vista que "ambos os lados são necessários para criar um espaço único de representação”. Em vista disso, o exemplo da dicotomia "povo/ancien régime", trabalhado em HSS e apresentado no início deste artigo, perde o seu sentido de exclusão radical. Por que o antagonismo não pode equivaler à exclusão radical? Primeiramente, porque nem todos os sentidos articulados por ambas as formações discursivas antagônicas precisariam ser necessariamente antagônicos; há, portanto, a possibilidade de se pensar que, apesar de antagônicos, os discursos podem compartilhar alguns sentidos.

Ainda mais. É o caso de significantes flutuantes, ou seja, significantes que flutuam entre os dois lados antagônicos e que são palco de disputas para se 
definir qual lado da fronteira antagônica conseguirá hegemonizar sentidos, sempre de forma contingente. Em discursos populistas, por exemplo, tal situação aparece muitas vezes de forma clara: considerando que o elemento básico do discurso populista é o apelo ao povo contra o establishment e que a vontade do povo é a própria expressão da democracia, movimentos populistas têm não raras vezes insistido que essa vontade do demos deve ficar acima de qualquer outro critério existente em democracias liberais, tais como liberdade de expressão, direitos individuais etc.. Neste sentido, entre o establishment democrático liberal e o discurso populista, o significante democracia assume a condição flutuante e torna-se objeto de disputa de significação hegemônica.

\section{Considerações finais}

A partir do acima exposto, que leitura podemos propor da categoria de antagonismo? Qual é o seu papel na teoria do discurso? Qual é o seu papel na teoria política?

Primeiramente, concordamos que o antagonismo perdeu claramente a sua primazia de HSS a partir da introdução da noção de deslocamento em $N R$. Não só a categoria de antagonismo perdeu a sua primazia mas também, com o próprio deslocamento, abriram-se novas possibilidades de se pensarem subjetividades políticas, ou seja, outros discursos que podem se constituir para dar conta do deslocamento da estrutura discursiva sem, no entanto, privilegiar o momento do antagonismo. Além disso, se o antagonismo, como o próprio Laclau já admitiu, não representa necessariamente uma exclusão radical, abre-se uma interessante oportunidade para pensarmos, num nível ôntico, essa categoria em contextos democráticos. Chantal Mouffe (2003, 2005) já vem fazendo isso em seus últimos livros com a introdução da categoria de agonismo.

Dessa forma, como afirmamos acima, em termos de análise política, devemos entender o antagonismo como o momento da percepção de uma ameaça. Tal percepção gera uma identificação entre elementos, e essa identificação produz um processo articulatório e, consequentemente, um discurso. Esse discurso constitui-se a partir da negatividade antagônica, mas, como suas operações são internas e o outro antagônico está fora de seus limites, os sentidos articulados, negativos e/ou positivos, fazem parte da própria forma como o sistema discursivo operará. 
Acreditamos que, regionalizando o antagonismo, novas possibilidades de pesquisa poderão ser abertas a partir da teoria do discurso como marco de investigação.

\section{Referências bibliográficas}

COLLETTI, Lucio (1975). "Marxism and the dialectic". New Left Review, vol. 1, n. 93, p. 1-29.

CRITCHLEY, Simon \& MARCHART, Oliver (comps.) (2008). Laclau: aproximaciones críticas a su obra. Buenos Aires: Fondo de Cultura Económica. HOMER, Sean (2005). Jacques Lacan. New York: Routledge.

HOWARTH, David (2000). Discourse. Buckingham: Open University Press. HOWARTH, David; NORVAL, Aletta J. \& STAVRAKAKIS, Yannis (eds.) (2000). Discourse theory and political analysis: identities, hegemonies and social change. Manchester: Manchester University Press.

HOWARTH, David \& STAVRAKAKIS, Yannis (2000). "Introducing discourse theory and political analysis", em HOWARTH, David; NORVAL, Aletta J. \& STAVRAKAKIS, Yannis (eds.). Discourse theory and political analysis: identities, hegemonies and social change. Manchester: Manchester University Press.

HOWARTH, David \& TORFING, Jacob (eds.) (2005). Discourse theory in European politics: identity, policy and governance. New York: Palgrave-Macmillan.

LACLAU, Ernesto (1990). New reflections on the revolution of our time. London: Verso.

(1993). Nuevas reflexiones sobre la revolución de nuestro tiempo. Buenos Aires: Nueva Visión. (ed.) (1994). The making of political identities. London: Verso. (1996). Emancipación y diferencia. Buenos Aires: Ariel. (2008). "Atisbando el futuro", em CRITCHLEY, Simon \& MARCHART, Oliver. (comps.). Laclau: aproximaciones críticas a su obra. Buenos Aires: Fondo de Cultura Económica.

(2008b). "Posfácio", em MENDONÇA, Daniel de \& RODRIGUES, Léo Peixoto (orgs.). Pós-estruturalismo e teoria do discurso: em torno de Ernesto Laclau. Porto Alegre: EdiPUCRS.

LACLAU, Ernesto \& MOUFFE, Chantal (1985). Hegemony and socialist strategy: towards a radical democratic politics. London: Verso. 
LUHMANN, Niklas (1998). Sistemas sociales: lineamientos para una teor ía general. Barcelona: Anthropos.

MOUFFE, Chantal (2003). La paradoja democrática. Barcelona: Gedisa.

(2005). On the political. New York: Routledge.

NORVAL, Aletta (1997). "Frontiers in question". Acta Philosophica, v. 2, p. 51-76.

(2000). "Trajectories of future research in discourse theory", em HOWARTH, David; NORVAL, Aletta J. \& STAVRAKAKIS, Yannis (eds.). Discourse theory and political analysis: identities, hegemonies and social change. Manchester: Manchester University Press.

STÄHELI, Urs (2008). "Figuras rivales del límite. Dispersión, transgression, antagonismo e indiferencia", em CRITCHLEY, Simon \& MARCHART, Oliver (comps.). Laclau: aproximaciones críticas a su obra. Buenos Aires: Fondo de Cultura Económica.

STAVRAKAKIS, Yannis (2003). "Laclau with Lacan: comments on the relation between discourse theory and Lacanian psychoanalysis", em ŽIŽEK, Slavoj (ed.). Jacques Lacan: critical evaluations in cultural theory. Volume III - Society, politics, ideology). London: Routledge.

TORFING, Jacob (1999). New theories of discourse: Laclau, Mouffe and Žižek. Oxford: Blackwell.

ŽIŽEK, Slavoj (1993). "Más allá del análisis del discurso", em LACLAU, Ernesto. Nuevas reflexiones sobre la revolución de nuestro tiempo. Buenos Aires: Nueva Visión.

\section{Resumo:}

"Antagonismo social" é uma das noções mais importantes e, ao mesmo tempo, de maior dificuldade de compreensão no âmbito da teoria do discurso. Uma das razões principais que dificultam seu entendimento reside no fato de que seus próprios formuladores, Laclau e Mouffe, têm apresentado reformulações para o conceito após a sua introdução original, em 1985. Tendo em vista principalmente a dificuldade acima referida, o objetivo do artigo é propor um exercício teórico em torno dessa categoria, a partir de um percurso pelos trabalhos de Laclau e Mouffe e de seus principais comentadores. Além disso, buscar-se-á apresentar uma nova leitura para o conceito, defendendo-se a ideia de que se deve compreendê-lo a partir do que chamarei de seu valor de identificação política.

Palavras-chave: antagonismo social; deslocamento; teoria do discurso; identificação política. 


\begin{abstract}
:
"Social antagonism" is one of the most important notions and, at the same time, the most difficult one to understand in the discourse theory. One of the most important reasons for that is the fact that the very formulators, Laclau and Mouffe, have been presenting reformulations to this concept after its earlier introduction in 1985. According to this referred difficulty, the aim of this article is to propose a theoretical exercise on this category, starting from Laclau and Mouffe's works towards the texts of their main commentators. Moreover, one intends presenting a new way to think this concept, arguing the ideia that this notion should be understood according to what I call its political value of political identification. Key-words: social antagonism; dislocation; discourse theory; political identification.
\end{abstract}

Recebido em 12 de novembro de 2011.

Aprovado em 10 de maio de 2012. 